SHS Web of Conferences 6, 03002 (2014)

DOI: $10.1051 /$ shsconf / 20140603002

(C) Owned by the authors, published by EDP Sciences, 2014

\title{
Research on Sichuan Cuisine Enterprises Crisis
}

\author{
Nan Jianfei ${ }^{1}$, Zhao Lili ${ }^{2}$ \\ ${ }^{1}$ Antai College of Economics \& Management, Shanghai Jiao Tong University, 200052 Shanghai \\ ${ }^{2}$ Faculty of Tourism and Food, Shanghai Business School, 200235 Shanghai, China
}

\begin{abstract}
It is impossible to avoid crisis for Sichuan cuisine enterprises. On the basis of emphasizing the importance of the research of Sichuan cuisine enterprises crisis, the paper mainly analyzed the issue of Sichuan cuisine enterprises crisis from three aspects including formation mechanism of Sichuan cuisine enterprises crisis, the impact mechanism of Sichuan cuisine enterprises crisis and its response measures(such as principles, methods and strategies)in order to provide an important reference so that Sichuan cuisine enterprises have a correct understanding of the crisis, effectively response to the crisis, and strengthen crisis management so as to achieve their scientific development themselves. To some extent, the paper is helpful to cope with the crisis and promote the safety operation of the enterprises which are facing the crisis.
\end{abstract}

Keywords. Sichuan cuisine enterprises; crisis; diagnostic analysis; specific countermeasures; enterprise management

\section{Introduction}

\subsection{Background}

As the characteristics of the local economy in Sichuan Food Province - Sichuan Food, the local culture and economy of Sichuan Food has been playing a very important role, led to the development of Sichuan Food Sichuan Food development of tertiary industry, formed a unique Sichuan Food economy. According to statistics, in 2008, the Sichuan Food restaurant industry sales of over 90 billion yuan, accounting for nearly $20 \%$ of the proportion of the total retail sales of social consumer goods reached $27.4 \%$, the contribution rate of growth in total retail sales of social consumer goods. With the advance of economic globalization, Sichuan cuisine enterprises as an important part of the service industry has become a new growth point of the Sichuan Food Province, the national economy and foreign trade, the more play in promoting the steady growth of the national economy, the prosperity of the market, and expand exports and more important role.

Corporate crisis are not willing to encounter every enterprise, but inevitable. As a management guru said: "The crisis is like taxes and death as inevitable". For enterprises, it is inevitable to how to effectively respond to the crises and manage crises. Sichuan cuisine enterprises as a specific type of business, every business must face the crisis facing the same problem.

Catering services is one of the pillar industries in Sichuan Food Province. However, on May 12, 2008 Wenchuan earthquake, making all walks of life in Sichuan Food Province has been a huge hit the Catering Hospitality Industry situation is at a standstill for some time. Not only that, the impact of secondary disasters such as earthquake, aftershocks, and earthquake prone, especially the financial 
crisis sweeping the globe, a flow of oil trench event of Sichuan cuisine enterprises and even catering services in Sichuan Food manufacture a new crisis, which makes including catering services in Sichuan Food Sichuan cuisine enterprises, including how to deal with the crisis, and how to strengthen the crisis management issues, has become the focus of academic attention inside and outside the province, many Sichuan Food enterprise managers and food service management research.

Facing the same crisis, Sichuan cuisine enterprises equally, why some enterprises fail due to the crisis and even demise it? Such as the Sichuan Food interpersonal days Corporation affected by the crisis, in October 2008, took to the auction platform and gradually faded from sight. However, the same Sichuan cuisine enterprises, why some enterprises due to the crisis and turnaround and rapid development? Sea fishing company has turned the corner, turn adversity into opportunity, to achieve scientific development, sound and rapid development and sustainable development.

It is based on the above background and reality confused, we are relying on the scientific research of the Sichuan Food Province, philosophy and social science research base - the Countermeasures (late subsidized No. CC09SJ11) Sichuan cuisine enterprises face crisis subject to carry out special studies.

\subsection{Significance}

Diagnosis and strategies to strengthen the Sichuan Food corporate crisis is not only urgent and of great theoretical value and practical significance of the main problems: (1) help Sichuan cuisine enterprises to identify and guard against operational risks, and to develop scientific measures, and effective response to the crisis, turn crises into opportunities, and promote the healthy development of the Sichuan Food Dining Hospitality Industry. (2) to help Sichuan cuisine enterprises to implement the scientific concept of development, adhere to accelerate the development of scientific development, sound and rapid development, better obey service "two speed" (ie, speed up the construction of the post-disaster nice new home, to speed up the construction of the western economy development Heights), Sichuan Food Catering Hospitality Industry early recovery of the overall revitalization. (3) contribute to the enrichment and development of catering enterprises at home and abroad of crisis management theory, help to guide post-disaster Sichuan Food Dining Hospitality Industry work, provide for its safe operation of the scientific concept of development and operational guidance; government departments at all levels, decision layer, managers and other important decision-making as well as research institutions, institutions of higher learning researchers who are interested in this field provide valuable thinking, reference and reference. In addition, to carry out this study, it can also make Sichuan Food the catering business community and theorists identity and the importance of the research of corporate mistakes and failures, and to encourage more business managers to explore the crisis early warning management law, Sichuan cuisine enterprises scientific development, harmonious development and sustainable development.

\section{Diagnostic analysis and specific countermeasures of Sichuan cuisine enterprises crisis}

\subsection{The formation mechanism of Sichuan cuisine enterprises crisis}

Sichuan cuisine enterprises crisis due to the disharmony between Sichuan cuisine enterprises changes of the external environment and internal conditions itself changes as well as outside the enterprise environment and internal conditions, resulting in Sichuan Food internal caught a survival predicament, it usually will give Sichuan Food the enterprises bring greater losses, and even lead to bankruptcy of the enterprise. Crisis events include the earthquake in Wenchuan, H1N1 and the event of waste oil, etc.

Formation mechanism research Sichuan cuisine enterprises crisis, more in-depth grasp of the reasons for the formation of the corporate crisis, help Sichuan cuisine enterprises of corporate crisis early warning, prevention and treatment as well as the crisis into opportunities. Comprehensive enterprise crisis management point of view of the three schools, two levels from the of enterprises 
external environment and internal conditions more systematic and comprehensive analysis of the mechanism of the formation of China's Sichuan cuisine enterprises crisis, on this basis, we propose a the Sichuan cuisine enterprises crisis formation mechanism of model as shown in the following figure

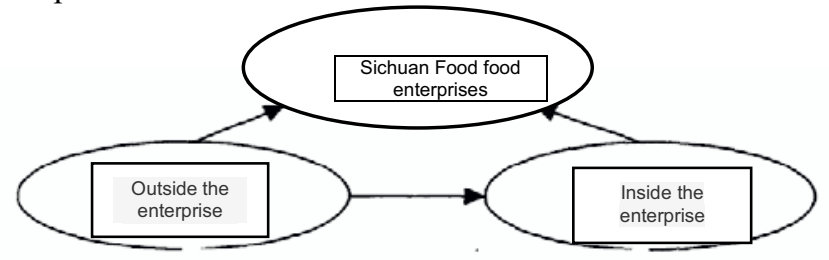

Figure 1. Formation mechanism of Sichuan cuisine enterprises crisis

\subsection{The influencing mechanism of Sichuan cuisine enterprises crisis}

\subsubsection{Influencing factors}

Sichuan Food corporate crisis formation mechanism of two basic elements: enterprise external environmental elements and internal conditions elements. The formation mechanism of the Sichuan cuisine enterprises crisis, first of all, the changes in the external environment from Sichuan cuisine enterprises led to corporate crisis may lead to corporate crisis from Sichuan Food internal conditions change. Third, the internal conditions of Sichuan cuisine enterprises and their external environment causes crisis.

The formation mechanism of the Institute of Sichuan Food corporate crisis, on the one hand from outside the enterprise environment of corporate crisis, the government's public policy, industry, market, cultural values, as well as natural disasters and other external environmental factors, including economic and legal. When sudden changes of the external environment, Sichuan cuisine enterprises the possibility of a crisis will increase. Sichuan cuisine enterprises in which the environment is currently a turbulent, complex and uncertain environment, which makes the inherently weak Sichuan cuisine enterprises inevitably face more crisis. On the other hand, the internal conditions of corporate crisis, including human resources, marketing, technology, finance, corporate strategy, as well as enterprise system. When some elements in the internal conditions are not conducive to the development of enterprise will have a potential crisis. Furthermore, the external environment can affect the internal conditions change thereby affecting corporate crises. In other words, Sichuan Food corporate crisis occurred mainly among the enterprise and changes in the external environment is the direct cause of Sichuan cuisine enterprises crisis. When Sichuan Food internal conditions suited to its external environment, it is likely to lead to their own crises

\subsubsection{Influencing ways}

Crises generally two ways to exert influence on the operation and development of the Sichuan cuisine enterprises: First, a direct role in Sichuan cuisine enterprises themselves, damage the image of Sichuan Food perception in the minds of consumers, destruction Sichuan Food supply market leading customer dining fluctuations in demand; Second, is applied to the source to affect the source to consumers, especially in the economic capacity of the target customer groups Sichuan cuisine enterprises, purchase intention, consumption patterns and psychological expectations directly undermine demand for catering services market

\subsection{The response measures of Sichuan cuisine enterprises crisis}

\subsubsection{Principles}

\section{1) Timely response}


A large number of corporate crisis cases in corporate crisis show that the parties enterprises to take positive action, the loss of all aspects of the enterprise reduced equivalent to the characteristics of the crisis: the corporate crisis is often sudden event, the development momentum for unpredictable destructive scope. In case of crises of Sichuan cuisine enterprises, they should take decisive measures to mitigate or eliminate the spread of the crisis in the shortest possible time.

\section{2) Protection}

Sichuan cuisine enterprises development is inseparable from the interests of the parties, the main customers, employees, investors, suppliers and various service agencies, governmental organizations, communities, the media and the public, etc.. These stakeholders and Sichuan cuisine enterprises have different interests. Interests of the Sichuan Food corporate crisis management core purpose is to protect the interests of the stakeholders, the starting point is to do everything possible to meet the crisis stakeholder interests.

\section{3) Prevention-oriented}

The precautionary principle is very important for the crisis managers who always adhere to the crisis management crisis prevention awareness, active crisis prevention preparedness, crisis signs of identification and early warning mechanism, strive to reduce the probability of crisis minimal loss to a minimum, crisis.

\section{4) Collaborative Command}

Corporate crisis is a special period and it is also a test of whether the enterprise has the ability to coordinate weather the storm period. The company can survive, the human, material and financial resources and the allocation of resources as well as various business activities of enterprises to participate in the handling of the crisis must be coherent, reasonable arrangements for the orderly functioning of the unified command of the division of labor to prevent making the situation worse.

\section{5) Priority communication}

The crisis communication refers to communication as a means to avoid the crisis, to defuse the crisis, to resolve the crisis, for the purpose of the process. The principles of crisis communication must always adhere to the requirements of crisis communication in corporate crisis management, effective use of a variety of communication tools to interact with the interests of all stakeholders needs point, in order to reduce the impact of the crisis on corporate.

\section{6) Timely conversion}

The crisis itself contains the opportunity, if the crisis faire regardless of the crisis will inevitably further expand, resulting in serious consequences: positive action, the correct response, and scientific decision-making, the crisis can be controlled, and, eventually, to eliminate the impact of the crisis. Transforming principle is an active, positive transformation crisis, the passive into active, to defuse the crisis in the bud through greater efforts to crisis communication, seeking external public support, even given the opportunity to creatively requires business managers to re-enhance corporate image.

\section{7) Learn to improve}

Learning principles, enterprise managers and all staff in crisis prevention, the entire process of crisis management and crisis aftermath, should continue to accumulate experience, reducing the crisis cost, improve crisis management capabilities, enhance the level of crisis management.

\section{8) Learn to emulate}

Stones from other hills may serve to polish jade. Draw on principle refers to enterprise managers and all staff in crisis prevention, crisis management and crisis aftermath of the whole process, to learn from the experience of advanced enterprise crisis management, especially peers and effective measures.

\section{9) Seeking the truth}

Refers to enterprise managers and all staff in crisis prevention, crisis management and crisis aftermath of the whole process, and should adhere to the principle of seeking truth from facts. On the 
one hand, it is necessary to have the type of scientific analysis of crisis events, their characteristics, formation mechanism, influencing mechanisms and the nature of hazards. On the other hand, the corporate should take practical and effective countermeasures in these crises.

\subsubsection{Methods}

Based on the latest research results of the theory of crisis management, this study follows two different types of repair methods:

\section{1) Repair method under the Defensible Sichuan cuisine enterprises crisis response.}

This crisis is outside the enterprise environment imposed on enterprises; enterprises are innocent victims. For this type of crisis, Sichuan cuisine enterprises can take the following fix: First, positive clarification. Means the and Sichuan cuisine enterprises held a news conference, released an open letter, etc., the real catering services to the media and the general public to provide evidence and information security, to clarify how the food quality and service quality to meet the relevant standards and safety. It is proactive in public events for waste oil so that the enterprise should clarify the facts. The second is an effective intervention. Price promotions for the global economic crisis, for example, can be carried out, in order to better attract lower-middle class. Wenchuan earthquake, for example, the strength of the Sichuan cuisine enterprises can take donations strategy to demonstrate corporate social responsibility, win more consumers Sichuan Food corporate brand identity.

\section{2) Repair method under the indefensible Sichuan cuisine enterprises crisis}

This crisis is generated by the internal environmental conditions; enterprise intentionally or victimizers. For this type of crisis, Sichuan cuisine enterprises can take the following fix: First, actively corrected. Sichuan Food enterprise take corrective measures, apologize compensation, returns, replacement, etc. The common feature of these behaviors enterprises seem to crisis at fault, and are taking steps to rectify the situation. Events such as food safety and quality, Sichuan cuisine enterprises not only should try to start from the source, and constantly improve the quality of food and beverage products and service standards to reduce customer distrust. The second is an effective intervention. Service refinement activities and food and beverage price promotions, such as can be carried out to better attract lower-middle class. It is necessary to participate in a variety of public welfare, such as the donation activities to repair damaged corporate image, in exchange for the consumer preferences of Sichuan Food corporate brand.

\subsubsection{Strategies}

\section{1) Establishment of a crisis management team}

The establishment of a crisis management team is to enable enterprises to face the crisis with a strong command of the core. The crisis management team is the leadership of departments and offices of the crisis management. By the corporate top management as well as the person in charge of the various functional departments of enterprise-based, integrated part of the junior staff intervention, there should be the best external senior public relations consultant. According to the circumstances of the incident, you can set up a leading group and office, but also set the person or group responsible for the accident investigation, processing and reception work. The members of the group should be good at observing longer than communication, innovation and courage to the people responsible. They must be able to understand the truth of the incident and the whole story for the first time, and is closely monitoring developments about the incident public information, including the media reflect the victims of the public, community groups, government public reflect internal employees emotional; analyzed the information to form processing program, seek truth from facts, accurately and timely reported to the core of enterprise management. And decision-making identified treatment program implemented quickly; summarized as the primary source of information throughout the crisis event. We should Process and release relevant information. Untrue and harmful rumors correct, to control the direction of public opinion. 


\section{2) Investigate the case}

Enterprises in the face of crisis, you can not turn a blind eye, but to immediately investigate the case, a plan to control the development of the situation, which is the most critical first step in crisis management. In order to show the care and attention of the corporate crisis, corporate managers must not only immediately external statement, and conditions allow, but also personally so easy to ease public antagonism, understanding and respect of the public and the media.

\section{3) Expert intervention to develop countermeasures}

First, relevant personnel in the handling of the crisis, in particular the participation of experts, the organize should set up a crisis management team, the situation of crisis to do a comprehensive analysis: What are the causes of the crisis? How the development status and trends of the crisis? What is the public affected? What is the external diffusion of crisis information dissemination channels and scope? The above problems, the development of the crisis management program, namely, how to treat the public, how to deal with the media, how specific actions.

\section{4) Appease the public and ease the situation}

Enterprises serious abnormal situation, especially significant responsibility for the accident and the damage to the public interest, the enterprise must have the courage to take responsibility, to appease the victims of public and give the public a certain spirit of compensation and material compensation for their understanding and sincerely, the crisis more there may be successfully resolved. For example, customers or the public is hurt because of the use of the company's products, businesses should be the first time an apology to show sincerity, to quickly recall the products in question at all costs, to improve the quality of products and services in a timely manner, but also description of the developments in the situation in a timely manner to the consumer. We should quell public outrage so as to win the goodwill of the public.

\section{5) Contact the media to guide public opinion}

After the Crisis incident, all kinds of rumors, speculation will be followed, the media also have reported. At this time, the business organization should be set up, "the spokesman, held a press conference in the emergence of crises in a timely manner or reporter conference to introduce the truth as well as the ongoing remedial measures to the enterprise and beyond public good contact with the media so in a timely manner accurate reporting. In order to influence the public and guide public opinion, the incorrect negative public reflect and public opinion into the correct, positive public reflect and public opinion. We should pay more attention to effective communication management in order to carry out an effective crisis management, because the external public views on the crisis depend on what they observe. In Western countries, the modern enterprise generally commissioned by some of the public relations department of the similar consulting firm intermediaries, the long-term to maintain a good relationship of cooperation with the media, once the corporate crisis can quickly and timely to organize and mobilize the media to carry out corporate propaganda offensive, the crisis may spread to a minimum. Of course, we must fight for the cooperation of other public, community and authority to help resolve the crisis. This effective strategies and techniques that we should take can help to increase of Sichuan Food corporate public trust.

\section{Conclusion}

Corporate crisis is inevitable so that the enterprise should try to manage its crisis. It is imminent for Sichuan cuisine enterprises in terms of the implementation of the "going out" strategy to have a correct understanding of the crisis, effectively response to the crisis, and strengthen crisis management, promote their safe operation so as to achieve their scientific development themselves.

\section{Acknowledgement}

A planning project is funded by Sichuan cuisine enterprises Development and Research Center (NO 
CC09SJ11)

\section{References}

1. Nan Jianfei, Zhao Lili. Customer-missing diagnostic analysis and countermeasures, Economics and Management, vol. 6, 2002 (11), pp.68-70.

2. Chen Yunchuan. Dining marketing. Higher Education Press, 2003.

3. Liu Furong, zhulin. Neighbor corporate crisis management. Enterprise management, vol.1, 2003 (8), p p.42-45.

4. Chen Guang Chao, Yao Xiaosheng. Corporate crisis management. Jinan University (Social Science Edition), vol. 2, 2004 (1), pp.23-26. 